\title{
Making Sense of Errors Made by Learners in Mathematical Word Problem Solving
}

\author{
Percy Sepeng ${ }^{1}$ \\ Sithembile Sigola ${ }^{2}$ \\ University of South Africa \\ E-mail: sepenp@unisa.ac.za1 \\ E-mail: sigola2007@yahoo.com
}

\section{Doi:10.5901/mjss.2013.v4n13p325}

\begin{abstract}
In recent years research in mathematical word problems has focused on an attempt to connect classroom mathematics teaching and learning to learners' out-of-school 'real life' knowledge. The study reported in the current article investigated sources of errors that Grade 9 learners make when they solve mathematical word problems in a classroom. The study followed a quantitative approach with data collected through a test. The study consisted of a convenience sample of 35 Grade 9 learners with different academic achievements in mathematics. Analyses of data gathered from learners' written work (or a test) seemed to suggest that learners encountered difficulties in reading and making sense of the mathematical word problems. In addition, it appeared that learners struggled to comprehend the given word problems. In brief, the data in the current article demonstrated that the errors exhibited by learners in the solution of word problems appeared to be as a result of lack of understanding of mathematical vocabulary that is used in a problem statement.
\end{abstract}

Keywords: mathematical errors; word problems, sense-making, problem solving, mathematical vocabulary

\section{Introduction}

Word problems have been defined differently by researchers. Adams (2003) defined word problems as "mathematical problems presented in a context of a story or a real life" (p. 790). He pointed out that learners need to possess some skills in order to interpret the given information into mathematical symbols. Similarly, Ahmad (2010) defined a word problem as a story problem that requires learners to translate the concrete to the abstract and the abstract to the concrete. According to Ahmad, problem solving involves a rigorous thought process that is coupled with concrete imagery. On the other hand, Palm (2009) defined mathematical word problems as mathematical tasks that are 'dressed up' in a real-world situation requiring the students to 'undress' and solve them. For the purposes of the study reported in the current article, we have used all the definitions were used in order to make meaning to how learners view word problem solving in mathematics classrooms.

Solving of mathematical word problems is a process requiring multistep skills and strategies (Landi, 2009). Learners are expected to understand the language and factual information given in the problem, to translate the problem into a numeric equation, and devise a plan that can be used to solve the problem (Leh, Jitendra, Caskio \& Griffin, 2009). As a result, learners seem to view word problem solving as a difficult task. These researchers demonstrated that for a learner to be an effective problem solver, it is essential that these skills be developed. As such, problem solving is a process that is grounded on reasoning rather than computation (Sepeng, 2011a; Sepeng \& Webb, 2012). Gravemeijer (1997) argued that mathematical word problems should promote sense making rather than computational proficiency. However, reports by scholars in mathematics education have struggled with the notion of 'real life' in relation to word problems in school mathematics (see, for example, De Corte, Verschaffel \& Greer, 2000; Garii \& Okum, 2008; Gerofsky, 2010; Sepeng, 2011a, 2011b; Sepeng \& Webb, 2012).

\section{Literature Review}

This section provides an overview of the role of word problem solving with the contexts of school mathematics curriculum. Then it discusses the nature of errors made by learners during the process of word problem solving, and finally it presents a notion of word problem solving in mathematics classrooms. 


\subsection{Role of word problem solving in the curriculum}

Problem solving is considered to be one of the main objectives of teaching school mathematics. The new South African Curriculum Statement (CAPS) places emphasis on teaching of problem solving to all grades (Department of Basic Education [DBE], 2011). The aim of the curriculum is to create a learner who "is able to acquire and apply knowledge and skills in ways that are meaningful to their lives." (DBE, 2011, p. 3). The new curriculum requires the incorporation of everyday contexts into the mathematics classroom, thereby making mathematics to be relevant and meaningful to the learners (Xin, 2009). The inclusion of word problems in the curriculum is vital as it serves as a key role in developing students' problem solving abilities. According to Kilpatrick, Swafford and Findell (2011), mathematical problem solving is one of the most central aspects of mathematics. They argued that problem solving enables learners to make sense of how mathematics can be of use in a daily life. De Corte, Verschaffel and Greer (2000) the inclusion of word problems in the school curriculum is a result of their potential to develop students' skills of knowing how to use their mathematics to approach and solve problems in practical situations. Leh, Jitendra, Caskio and Griffin (2009) demonstrated that word problem solving leads to understanding as it enables learners to connect different meanings, interpretations and relationships.

\subsection{Errors made by learners in word problem solving}

Zakaria and Yusoff (2009) argued that learners make errors not because they are weak, but attribute these errors to a lack of strategies that can be used to solve problems. They concluded that learners did not understand the questions and as a result they were unable to implement the correct strategies to a solution. In addition, these researchers attributed learners' failure to engage with the problem statement to exposure in answering procedural problems that involved minimal steps. In addition, Zakaria and Yusoff (2009) noted that errors occurred because learners were applying rules without understanding basic concepts involved. Mathematics educators are probably doing little to nurture the learners' abilities to develop effective strategies that could be used to solve word problems. Kilpatrick et al (2001) proposed that children can be assisted to acquire advanced mathematical knowledge if they (learners) spend time practicing the required skills. Perhaps as mathematics educators, we seem not to offer the learners enough exercises to enhance components of problem solving such as decoding and interpreting. In most cases learners are expected to solve word problems without mastery of these skills.

\subsection{Word problem-solving and errors made by learners}

Research has shown that learners make errors when solving mathematical word problems. A number of researchers have shown that learners are failing to engage with the word problems due to failure to comprehend the problem statement (Barnes, 2005). Other aspects of learner difficulties in word problem solving include the findings by Ahmad's (2010) study which illustrated that the form four learners in Malacca made errors in their solution processes because they struggled to correctly translate word representations into mathematical representation. He also noted that lack of visualization or inability to derive 'concrete images' by the learners often led to inability to reason mathematically. Other studies (Sepeng, 2011a; Sepeng \& Webb, 2012; Verschaffel, Greer, \& Van Dooren, 2009) reported that learners have tendencies to exclude real world knowledge when solving word problems. Learners could not see a connection between the mathematics at school and their everyday life mathematics.

\section{Research Methodology}

In The study in which this article is based followed a quantitative approach. Quantitative data were gathered via a test comprised of seven word problems. The overall data sought to assist in answering the following research questions:

- What types of errors do learners make when solving mathematical word problems?

- What are the sources of these errors?

\subsection{Reserch design}

Punch (2009) defines a research design as a plan of how the research project would be conducted. This study reported here focused on exploring errors made by the learners in their solution processes when they engage in mathematical 
word problem solving. To do this, a test on word problems was administered to a convenience sample of 35 learners in a Grade 9 classroom. The participating learners wrote the test after school hours in a presence of the researchers. Learners were asked to explain their reasoning and thinking in writing after solving each item of the test. The rationale behind this was to present learners with opportunities to immediately reflect on how and why they solved the problems the way they did during problem-solving process. The learners' written work (test scripts) were marked and then later analysed according to question numbers that resulted in themes. Purposive sampling is essential as it allows the researcher to sample in a deliberate way with a purpose or focus in mind (Punch, 2005). In a study reported here, purposive sampling enabled us to select cases that were unique and informative, cases that were used to gain deeper understanding of the nature and causes of errors made by learners (Neuman, 1994).

\subsection{Ethical considerations}

According to Du Plooy (2002) it is important that any research involving people as subjects, respondents or participants specify how their human and civil rights will be protected. In carrying out this study discussed in the current article, permission had to be sought from the Gauteng Department of Education as well as a principal of a school where the research was conducted. Participant information sheets, consent forms for both learners and parents were distributed to the Grade 9 classroom. The information sheet provided the learners and parents with adequate knowledge on the data collection methods and the information sheets were written in a language that is understandable to the participants. Learners were assured to exercise their rights to withdraw from the study should they decide to do so at any time. Participants were also assured that identities will be concealed and also that information collected will be used for research purposes.

\section{Results}

\subsection{Qualitative data}

Most The learners' responses produced from a test results were classified into four categories:

- Mathematically accurate (MA): are those cases that were mathematically correct and considered reality of the problem statement;

- Partially correct (PC): all responses that were either mathematically correct or cases were situation of a problem statement was considered, or visa versa.

- Incorrect responses (IR): responses by the learners have been classified as mathematically inaccurate and suspended reality of the problem statement; and

- No response (NR): instances were no solution to a word problem was given.

We used the data in the table to discuss learners' performances to each word problem (WP). Descriptive analyses were done using the frequencies $(f)$ and percentages.

Table 1. Summary of the test analysis

\begin{tabular}{ccccccccc}
\hline & \multicolumn{2}{c}{ MA } & \multicolumn{2}{c}{ PC } & \multicolumn{2}{c}{ IR } & \multicolumn{2}{c}{ NR } \\
\cline { 2 - 9 } & $f$ & $\%$ & $f$ & $\%$ & $f$ & $\%$ & $f$ & $\%$ \\
\hline WP1 & 10 & 29 & 0 & 0 & 25 & 71 & 0 & 0 \\
\hline WP2 & 19 & 54 & 11 & 32 & 5 & 14 & 0 & 0 \\
\hline WP3 & 8 & 23 & 5 & 14 & 18 & 52 & 4 & 11 \\
\hline WP4 & 10 & 29 & 6 & 17 & 16 & 46 & 3 & 9 \\
\hline WP5 & 4 & 12 & 4 & 12 & 26 & 74 & 1 & 2 \\
\hline WP6 & 3 & 9 & 3 & 9 & 24 & 68 & 5 & 14 \\
\hline WP7 & 5 & 14 & 4 & 12 & 19 & 54 & 7 & $\mathbf{2 0}$ \\
\hline Mean & & 24 & & 13 & & 54 & & 9
\end{tabular}

\subsubsection{Descriptive analysis of WP1}

WP1: Sizwe bought 4 planks of 2.5m each. How many planks of 1 meter $(\mathrm{m})$ can he saw out of these planks?

WP1 required learners to find the number of $1 \mathrm{~m}$ planks that can be obtained from a $2.5 \mathrm{~m}$ plank. Learners were 
expected to be aware of a real-life situation used in a word problem statement where a $2.5 \mathrm{~m}$ planks are separate and need to be cut as they are instead of combining (or joining) the planks to obtain $10 \mathrm{~m}$. An analysis from the table shows that $29 \%$ (10) of the response was mathematically correct, while $71 \%(25)$ of the responses were incorrect. Analysis of the learner's responses indicates that $29 \%$ of the solutions given did consider reality in their solution processes. In other words, learners were aware that from each 2,5metre plank they could obtain 2 metres and obtained a correct solution.

Some of the responses given were mathematically correct but inappropriate because reality was not considered. These learners solved WP1 as a standard mathematical problem and failed to consider reality. These learners (49\%) could not realise that when planks are cut out to a required length, the remaining pieces may not be re-used within a context used in WP1. It was interesting to note that few learners used models to solve the WP1. The use of pictures and diagrams to portray the items in the problem could be seen in learners' scripts as a strategy to obtain a correct solutions. However, the observation was that most learners were not successful in producing correct solutions because their models did not work. Of the 31\% that modelled their answers, $27 \%$ of the learners produced incorrect solutions. The extract below is an example of such a case for WP1 solving, due to what appeared as an inability to successfully model the problem:

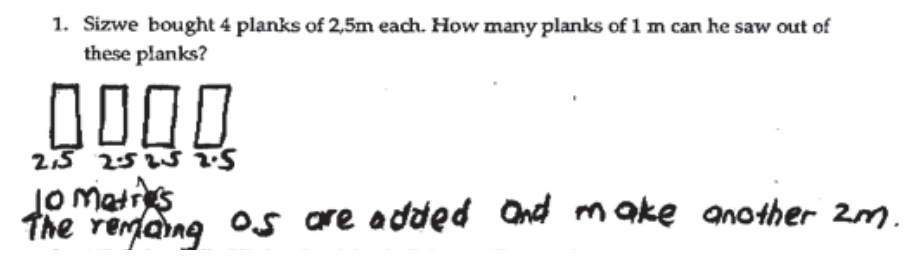

Most of the learners added all the 4 planks to obtain $10 \mathrm{~m}$. Such learners were not aware, as noted earlier, that in a real life situation a plank that has been cut out may not be combined to obtain a $1 \mathrm{~m}$ plank that will work in such contexts used in WP1 task. The learner appeared to have made efforts in using modelling of a problem but without success.

\subsubsection{Descriptive analysis of WP2}

WP2: 445 Gainesville High school football fans will go to the stadium by bus. Each bus can hold 36 fans. How many buses will be needed?

Table 1 showed that $54 \%$ (19) of the responses were mathematically accurate, $32 \%$ (11) were partially correct responses while $14 \%$ (5) gave incorrect responses. The primary objective of this question was to enable the learners to make sense of the problem, and just like the previous one required learners to include real-world knowledge in their solution of word problems. The data in Table 1 depict that majority of the learners were able to find correct solutions and take reality into considerations. They were aware that one cannot obtain a fractional number of buses and hence obtained correct solution. However some of the pupils excluded reality in their solution processes.

It was observed that some of the learners (about 40\%) obtained mathematically accurate solutions (12.36) to WP2 but struggled to consider reality of the problem situation used (that 13 buses are needed). There was instances where learners gave fractional answers as the number of buses. After solving the word problem, learners were satisfied with the solution obtained and there was no verification of the solution to determine feasibility. Even for those answers that appeared ridiculous, pupils seemed satisfied with the solutions. The extract below shows an incorrect response that is a result of failure to take reality into consideration:

\subsubsection{Descriptive analysis of WP3}

WP3: If the product of 2 and 4 is subtracted from twice a certain number the result is 22 . Find the number.

In WP3 task, learners were expected to use mathematical language and the language used for instruction (English) in order to make sense of a problem statement. In addition, WP3 created a space for learners to demonstrate the ability to translate a given problem to a mathematical equation and in a process, measure learners' problem solving abilities. Table 1 indicate that $23 \%$ (8) of the responses were mathematically accurate, $14 \%$ (5) were partially correct, $52 \%$ (18) were incorrect while $11 \%$ (4) did not respond.

In WP3, a word product is used in ordinary English and has a different meaning in mathematics. The purpose of this problem statement was to find out if mathematical vocabulary has an effect on learners' solution of mathematical 
word problems. Learners' responses indicate that $40 \%$ of the learners were not able to find the product of the given numbers. Of the $60 \%$ who succeeded in calculating the product of the numbers, $31 \%$ of the responses were mathematically inaccurate.

The analysis of learners' responses indicated that learners lacked problem solving skills. From the participating learners, $77 \%$ could not make sense of a problem statement. These learners struggled to formulate the correct equation while some of the learners who managed to formulate the correct equation could not solve the equation correctly. This may be attributed to a lack of knowledge of the strategies that could be used to solve the word problem. The extract below shows an incorrect response that appeared to be due to lack of problem solving strategies that could have been employed.

3. If the product of 2 and 4 is subtracted from twice a certain number the result is 22. Find the number

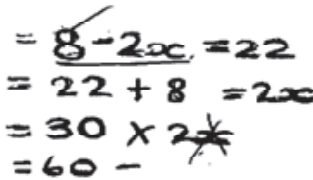

The extract above shows that the learner was able to find the product of 2 and 4 , but was not able to formulate the correct equation and hence obtained a wrong solution.

\subsubsection{Descriptive analysis of WP4}

WP4: If 12 is added to 7 times a certain number the sum is 250 . Find the number.

Similar to WP3, learners were expected to use the mathematical vocabulary as well as to demonstrate ability to make sense of problem statement in word problem solving. $29 \%(10)$ of the responses were correct, $17 \%$ (6) were partially incorrect, and $46 \%$ (16) were incorrect while $9 \%$ (3) did not attempt to solve the problem.

Although this question appeared to have used simple language, it was observed that $57 \%$ of the learners could not either find 7 times a number or find the sum in order to formulate an equation. The indication is that mathematical language used in the problem statement may have contributed to the learners' inability to formulate mathematical equation that could be solved.

Although $43 \%$ of the learners were able to find seven times the number, $27 \%$ of these learners were not able to produce computationally accurate responses of the problem statement. The observation seems to suggest that learners lacked appropriate and effective strategies (or skills) required to solving equations successfully. It was also noted that even if learners obtain unreasonable (or nonsensical) answers, they did not check if the solutions make sense in real-life situations. The extract below was used as an example of a learner who formulated the equation successfully but was unable to correctly solve the word problem:

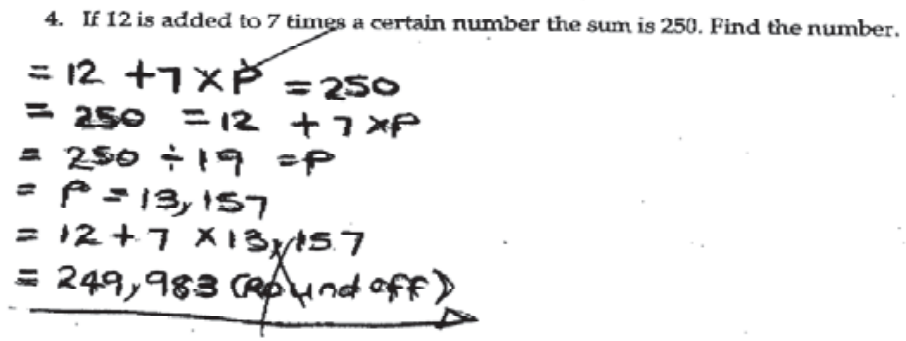

\subsubsection{Descriptive analysis of WP5}

WP5: Tumi bought a salad roll and a juice for lunch. The salad roll costs R2.40 more than juice and the total bill was R8.20. How much did the salad roll cost?

Table 1 show that $12 \%$ (4) of the responses were mathematically accurate, $12 \%$ (4) were partially correct, $74 \%$ (26) were incorrect while $2 \%$ (1) did not respond to a WP5. This question was intended to see if the learners are able to make use the given information and interpretation of a problem statement in order to find a correct solution. The learners' 
results in this question show that the majority of the learners obtained computationally incorrect and situationally inappropriate solutions.

Of the $12 \%$ of the learners who obtained correct responses, majority (88\%) of these learners could not successfully model the given word problem. It was also observed that learners merely worked out the solutions without understanding what they were doing. Of the learners who managed to produce correct solutions, it was observed that learners mainly did the computation and found the price of juice, without finding the price of the salad roll. The partial solving of a problem may be attributed to learners' inability to make meaning to a problem statement.

It appeared from the data that learners were not aware of problem solving techniques that they could employ in order to obtain solutions and did not view problem solving as something they are capable of use to solve the given word problem. WP5 required learners to use logical reasoning and could not be solved using only algorithmic methods. What was noted was that most of the learners struggled to produce a correct solution for the task.

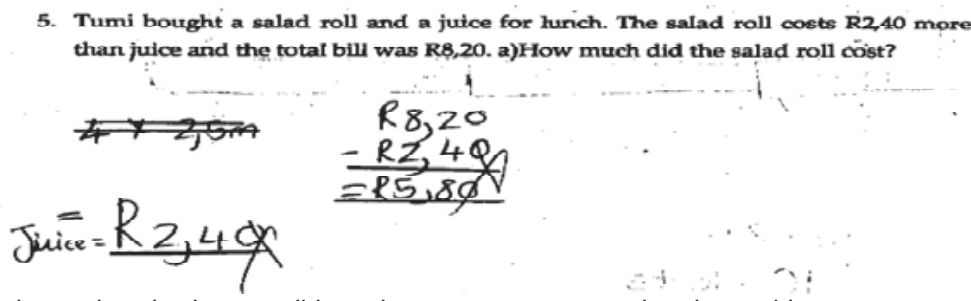

The above extract shows that the learner did not have a strategy to solve the problem statement. The learner made some calculations and obtained the answer. The question was not fully answered because the price of the salad roll was not calculated.

\subsubsection{Descriptive analysis of WP6}

WP6: A turkey costs 5 times as much as the chicken. A farmer bought 20 turkeys and 50 chickens for R1 200. Calculate the price of one turkey.

Similar to WP5, this problem was intended to find out if learners can model mathematical word problems. Data in Table 1 show that 9\% (3) of the responses were mathematically correct, 9\% (3) were partially correct, 68\% (24) were incorrect responses while the remaining 14\% (5) did not respond. Although this question appeared to have used familiar words in problem statement, most learners had difficulties in devising strategies that could be used to obtain correct solutions. The picture that was given here seems to be that of an indication that learners were not able to model word problems. The extract below shows learner's wrong response that is a result of lack of inability to model a word problem.

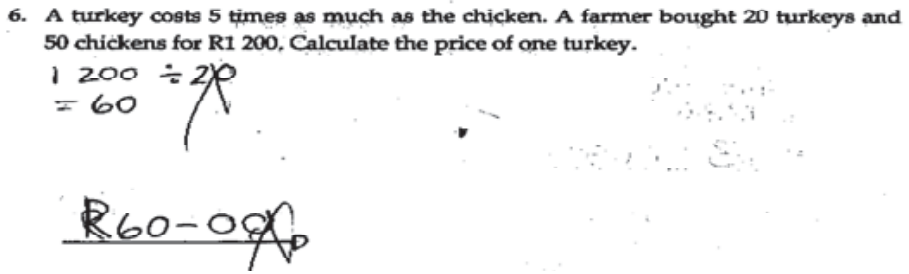

This was an incorrect response to the task. The learner simply used the given numbers to find a solution and in a process, suspended reality of the problem situation. It may be speculated that such a response may be as a result of failure to comprehend the problem statement or failure to use the given information to find a solution.

\subsubsection{Descriptive analysis of WP7}

WP7: A Makhosi buys a pencil, a pen and a book for which he pays a total of R53.10. If the price of the pen is twice that of a pencil and the price of the book is three times that of the pen, how much does each cost?

WP7 appeared to be the most challenging to the grade nine learners as shown earlier in Table 1. Data showed that only $14 \%$ (5) of the responses were computationally correct, $12 \%$ (4) partially correct, $54 \%$ (19) incorrect answers, while $20 \%$ (7) did not even attempt answering the question. In order to solve this word problem, learners had to read and 
understand the given information. Use of expressions such as the pen is twice the price of the pencil, and the book is three times the price of a pen confused the learners even further.

Learners could not translate the given statement into an algebraic expression that could be solved. Methods adopted by the learners are an indication that they lack problem solving skills, which in turn, may have been be due to inability to formulate equations and comprehend the language used. Learners' difficulties in solving this equation could have been exacerbated by the addition of the three variables. This question posed challenges to learners who were unable to relate the three variables and formulate equations. The extract below shows an incorrect response to a word problem which appeared to be as a result of lack of a suitable and appropriate strategy:

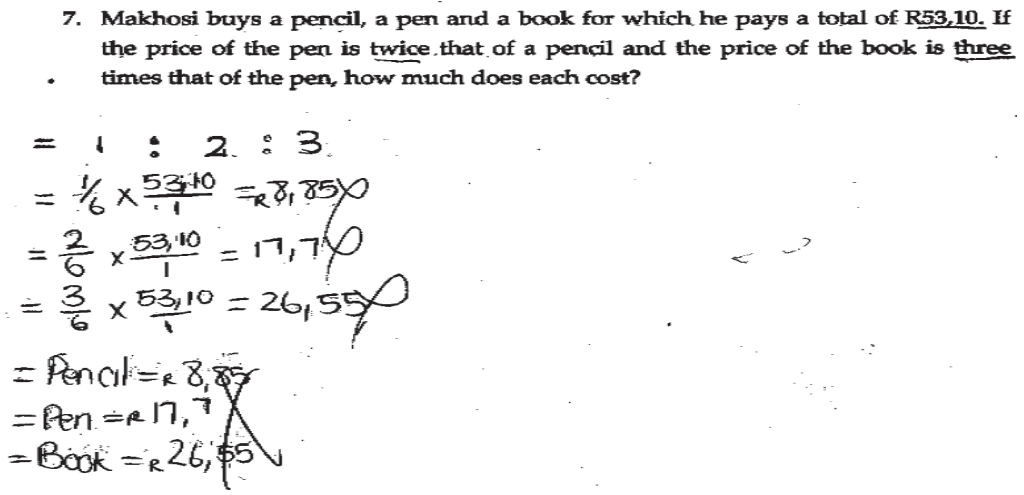

The learner could not relate the three variables and as a result resorted to using ratio to find the price of each item.

\section{Discussion}

The findings of a study reported in this article illustrated that learners encountered difficulties in reading and making sense of the mathematical word problems. In addition, it seemed that learners could not comprehend the given word problems and this might have been due to, but not limited to i) the language used in word problem statement; ii) the nature of the wording used in the word problem statement; and iii) and the magnitude of the words (word count) used in the problem statement, consistent with other reports (see for example, Cooper \& Harris, 2005; Saljo \& Wyndham, 1997). These researchers reported that errors occurred in the solution of word problems because of lack of understanding of mathematical vocabulary that is used in a problem statement. Another study by Zakaria and Yusoff (2002) showed that more than half the students that participated in the study could not comprehend the given word problems.

The findings of a study reported in this article seem to suggest that the source of the learners' errors lie in pedagogical practices employed in the mathematics classrooms (Sepeng, 2011b; Sepeng \& Webb, 2012). Faced with low learner academic achievement in South African school mathematics, it is important for mathematics educators to allow students to construct their own meaning as suggested by literature (Gerofsky, 2010; Gravemeijer, 1997; Schonfield, 1998). When teaching word problems, there is need to move away from using pedagogies that deny learners the opportunities to analyse the given word problems and the context that is embedded in it as suggested by Xin (2009). Pivotal to the success of these strategies is empowering the mathematics teachers with the relevant knowledge and appropriate skills that could be used to improve the quality of teaching word problems as proposed by Gravemeijer (1997).

\subsection{Use of words with multiple meanings (mathematical register).}

The other finding that emerged from our study discussed here was that the inclusion of words with multiple meanings in a problem statement can be a barrier to solving word problems. The results of the study showed that learners were unable to produce correct solutions because of failure to correctly decode the meanings of words from the given problem statement. As noted earlier, some of the learners could not find the solution to the word problem because they did not understand the meaning of the word product. Similar findings by other researchers (Adams, 2003) showed that use of words may pose a conflict to the learners unless thoroughly explained. As suggested by Acosta-Tello (2010) the sources of learners' errors can be located in methodologies that are not congruent to the assessments given to the learners. She 
argued that solving a word problem should not task the learners' reading skills. As such, she calls for mathematics educators to require learners to solve word problems that have a language level which learners have mastered.

\subsection{Syntactic features used in a word problem}

Data in this article demonstrated that some errors occurred as a result of the syntactic features that characterized the problem statement. The length of the word problem as well as the clauses that were used in question 7 proved to confuse the learners. The question contained phrases such as 'the price of the pen is twice that of a pencil and the price of the book is three times that of the pen.' and these phrases appeared to have contributed in distracting learners' thinking resulting in learners failing to engage with the word problem. In addition to the phrases used in WP7, the length of the problem statement contributed in bringing about errors. Learners performed better in word problems that were short and simply worded compared to those that are long. The finding that seemed to suggest that mathematical phrases that combine two or more mathematical concepts often pose challenges for the learners is consistent with Mousley and Marks' (1991) study. Verschaffel, Greer, \& Van Dooren's (2009) study confirmed similar findings that the size of the number of words used in a word problem can have an impact on the way learners engage in a word problem.

\subsection{Modelling and reality in word problem-solving}

A research study showed that learners exclude reality and common sense in their solution of word problems. These findings are similar to the study by Yoshida, Verschaffel and De Corte (1997) that showed learners' responses to the real-world problems excluded realistic consideration (Sepeng \& Webb, 2012). Of the 75 Japanese students that responded to the word problems, only $17 \%$ of the learners' responses could be considered to be realistic. The findings from the study by these researchers showed that reasons behind the learners' unrealistic solutions could be located in aspects of classroom practice. The study showed that classroom practice was characterized by use of impoverished and stereo-typed word problems which could be modelled by simple operations. Furthermore, it was shown that classroom practice put emphasis on computational proficiency at the expense of interpretive skills. Taking into account these findings is evident that there is need to have innovative classroom practices as suggested by De Corte, Verschaffel and Greer (2000). These researchers have advocated for an improvement in the type of word problems used in mathematical classrooms as well as the inclusion of reality in word problem solving. Such tendencies to exclude reality in word problem solving were shown by Garii and Okum (2008)'s study that was conducted on a group of K-6 educators whose results showed alarming concerns of educators' failure to connect the mathematics taught to the mathematical practices found outside the classrooms.

\section{Conclusion}

The study reported here has made us aware of the possible sources of errors in children's word problem solving. In light of the country's implementation of a new curriculum, these findings may help bring about the necessary changes to reform and innovate classroom practices. It is essential for learners to be assisted to acquire the necessary skills and strategies in order to successfully solve word problems. The findings seemed to suggest that the assessment designers of mathematical word problem tasks should consider the nature of language used in the problem statement as well as the situation selected for the task.

On the basis of the findings of a study at which this article is based, we suggest that the strategies that can be used for solving word problems must be made available to the learners particularly the use of models, pictures tables, diagrams and other learning aids. It is recommended that teachers incorporate the learners' everyday experiences in word problem solving. The study has demonstrated that mathematical language plays a vital role in learners' comprehension of word problems, hence the language that is used in mathematical word problems needs to be taken into cognisance. We therefore, suggest that teachers need to be empowered to help the learners to be conversant in the mathematical language. The mathematical register needs to be taught in order to help learners understand the meaning of words. Mathematical vocabulary may be included in the assessment tasks. In conclusion, it is recommended that the findings of the findings in the current should be brought to the attention of textbook authors in order to improve on the quality of mathematical word problems that are included in the school textbooks. 


\section{References}

Acosta-Tello, A. (2010). Making Mathematics Word Problems Reliable Measures of Student Mathematics Abilities. Journal of Mathematics Education, 3(1), 15-26.

Adams TL 2003. Reading Mathematics: More than words can say. The reading Teacher, 56(8), 787 - 795.

Ahmad, A., Tarmizi, R.A., \& Nawawi, M. (2010). Visual Representations in Mathematical Word Problem Solving Among Form Four Students in Malacca. Procedia Social and Behavioral Sciences, 8, 356-361.

Barnes, H. (2005). The Theory of Realistic Mathematics Education as theoretical framework for teaching low attainers in mathematics. Pythagoras, 61, 42-57.

Cooper, B., \& Harries, A.V. (2005). Making sense of realistic word problems: Portraying working class "failure" in a division with a remainder problem. International Journal of Research \& Methods in Education, 22, 449-463.

De Corte, E., Verschaffel, L., \& Greer, B. (2000). Connecting mathematics problem solving to the real world. Retrieved May, 162012. from http://math.uni.pa.it/ grim/Jdecorte

Department of Basic Education. (2011). Curriculum and Policy Statement Grades 10 - 12: Mathematics. Pretoria: Department of Basic Education.

Du Plooy, G.M. (2002). Communication Research: Techniques, Methods and Applications. Lansdowne: Juta \& Co.

Garii, B., \& Okumu, L. (2008). Mathematics and the World: What do Teachers Recognize as Mathematics in Real World Practice. The Montana Mathematics Enthusiast, 5, 291-304.

Gerofsky, S. (2010). The impossibility of 'real-life' word problems (according to Bakhtin, Lacan, Zizek and Baudrillard). Discourse: Studies in the Cultural Politics of Education, 31(1), 61-67.

Gravemeijer, K. (1997). Commentary Solving Word Problems: A Case of Modeling? Learning and Instruction, 7(4), 389-397.

Kilpatrick, J., Swafford, J., \& Findell, B. (2001). Adding it up: Helping Children Learn Mathematics. Washington DC: National Academy Press.

Landi, M.A.G. (2001). Helping Students with Learning Disabilities Make Sense of Word Problems. Intervention in School and Clinic, 37(1), 13- 18

Leh, M.J., Jitendra, A.K., Caskie, G.I.L., \& Griffin, C.C. (2009). An evaluation of curriculum-based measurement of mathematics word problem solving measures for monitoring third-grade students' mathematics competence. Assessment for Effective Intervention, $32,90-99$

Mousley, J., \& Marks, G. (1991). Discourses in mathematics. Geelong, Vic: Deakin University Press

Neuman, W.L. (1994). Social Research Methods: Qualitative and Quantitative Approaches. Boston: Pearson Education.

Palm, T. (2009). Theory of authentic task situations. In L Verschaffel, B Greer, W Van Dooren, S Mukhopadhyay (Eds.), Words and Worlds: Modelling verbal descriptions of situations. Netherlands: Sense Publishers, pp. 3-19.

Punch, K.F. (2009). Introduction to Research Methods in Education. California: Sage Publications.

Punch, K.F. (2005). Introduction to Social Research. California: Sage Publications.

Saljo, R., \& Wyndham, J. (1993). Solving everyday problems in the formal setting: An empirical study of the school as context for thought. In J L Seth Chalklin (Eds.), Understanding practice perspectives on activity and context. Cambridge: Cambridge University Press, pp. 327-342.

Schoenfield, A. (1998). Problem solving in contexts. In RI Charles, EA Silver (Eds.), Research agenda in mathematics education. The teaching and assessing of Mathematical problem solving. Reston, VA: National Council For Mathematics, pp. 82 -89.

Sepeng, P. (2011a). Modeling and Reality in Word Problem Solving. In M. Setati, T. Nkambule, \& L. Goosen (Eds.), Proceedings of the ICMI Study Conference: Mathematics and Language diversity, pp. 363-371. Sào Paulo, Brazil: ICMI.

Sepeng, P. (2011b). Reality based reasoning in word problem solving. In H. Venkat, \& A.A. Essien (Eds.), Proceedings of the $17^{\text {th }}$ National Congress of the Association for Mathematics Education of South Africa. pp. 223-237. Johannesburg, South Africa: AMESA.

Sepeng, P., \& Webb, P. (2012). Exploring mathematical discussion in word problem-solving. Pythagoras, 33(1),1-8.

Verschaffel, L., Greer, B., \& Van Dooren, W. (2009). Words and Worlds. Netherlands: Sense Publishers.

Xin, Z. (2009). Realistic problem solving in china: Students' performances, interventions, and learning settings. In L. Verschaffel, B. Greer, W. Van Dooren, \& S. Mukhopadhyay (Eds.), Words and Worlds: Modelling verbal descriptions of situations, pp. 161-176. Netherlands: Sense Publishers.

Yoshida, H., Verschaffel, L., \& De Corte, E. (1997). Realistic Considerations in Solving Problematic Word Problems: Do Japanese and Belgian Children have the same Difficulties? Learning and Instruction, 7(4), 329-338.

Zakaria E, Yusoff N, 2009. Attitudes and Problem-Solving Skills in Algebra among Malaysian Matriculation College Students. European Journal of Social Sciences, 8(2), 232-236. 
